\title{
Andrographolide Promotes Proliferative and Osteogenic Potentials of Human Placenta-Derived Mesenchymal Stem Cells Through the Activation of Wnt/ $\beta$-Catenin Signaling.
}

\section{Naruphong Phunikom}

Thammasat University Faculty of Medicine

Nittaya Boonmeun

Mahidol University Faculty of Science

Kanoknetr Suksen

Mahidol University Faculty of Science

\section{Pakpoom Kheolamai}

Thammasat University Faculty of Medicine

\section{Sirikul Manochantr}

Thammasat University Faculty of Medicine

\section{Chairat Tantrawatpan}

Thammasat University Faculty of Medicine

Duangrat Tantikanlayaporn ( $\nabla$ dkanlayaporn@gmail.com )

Thammasat University Faculty of Medicine https://orcid.org/0000-0002-1197-4957

\section{Research}

Keywords: Andrographolide, Placenta-Derived Mesenchymal Stem Cells, Osteogenic differentiation, Regenerative medicine

Posted Date: February 4th, 2021

DOl: https://doi.org/10.21203/rs.3.rs-168187/v1

License: (c) (i) This work is licensed under a Creative Commons Attribution 4.0 International License. Read Full License

Version of Record: A version of this preprint was published at Stem Cell Research \& Therapy on April 14th, 2021. See the published version at https://doi.org/10.1186/s13287-021-02312-x. 


\section{Abstract}

Introduction

The in vitro expansion and differentiation of mesenchymal stem cells derived from bone marrow (BMhMSCs) are considered as potential therapeutic tools for clinical applications in bone tissue engineering and regenerative medicine. However, invasive sampling and reduction in number and proliferative capacity with age are the major limitations of BM-hMSCs. Recently, human placenta-derived MSCs (PLhMSCs) obtained by a non-invasive procedure have attracted much interest. Attempts to increase the potential of PL-hMSCs would be an important paradigm in regenerative medicine. Herein, we examined the proliferative and osteogenic effect of andrographolide (AP) on PL-hMSCs.

Methods

Mesenchymal stem cells were isolated from full-term normal human placentas and were characterized before using. Cell cytotoxicity and proliferative effect of AP were examined by MTT and BrdU assay, respectively. The non-toxicity concentrations of AP were further assessed for osteogenic effect determined by alkaline phosphatase (ALP) expression and activity, alizarin red staining, and osteoblastspecific gene expressions. Screening of genes involved in osteogenic differentiation related pathways modulated by AP were explored by a NanoString nCounter analysis.

Results

PL-hMSCs generated in this study met the MSCs criteria set by the International Society of Cellular Therapy. AP has no cytotoxic effect on PL-hMSCs up to $10 \mu \mathrm{M}$. The compound increased PL-hMSCs proliferation concomitant with increases in Wnt/ $\beta$-catenin level and activity. It also enhanced osteogenic differentiation in association with osteoblast-specific mRNA expression. Further, AP promoted bone formation and increased bone structural protein level, osteocalcin, in osteoblastic cells. Gene screening analysis showed the upregulation of genes related to Wnt/ $\beta$-catenin, TGF $\beta / B M P, S M A D$ and FGF signaling pathways.

\section{Conclusion}

We demonstrated, for the first time, the potential role of AP in promoting proliferation, osteogenic differentiation, and osteoblast bone formation of PL-hMSCs. This study suggests that AP may be an effective novel agent for the improvement of PL-hMSCs and stem cell-based therapy for bone regeneration.

\section{Introduction}

Bone degenerative diseases as well as osteoporosis have substantial impact on the quality of life and are major public health challenges [1, 2]. Bone marrow-derived mesenchymal stem cells (BM-hMSCs) have a direct role in the maintenance of bone balance and act as a source of progenitors for osteoblasts, which 
are responsible for bone formation and as regulators for osteoclastogenesis [3]. A decline in the number of BM-hMSCs is one of the important factors contributing to age-related bone loss, such as postmenopausal osteoporosis, because of a reduction in proliferative capacity accompanied by a decrease in osteogenic differentiation potential [4, 5]. BM-hMSCs are, therefore, considered as potential therapeutic tools for clinical applications in bone tissue engineering and regenerative medicine due to their beneficial characteristics including high self-renewal and differentiation abilities as well as low immunogenicity properties [6-9]. Nevertheless, major restrictions for clinical uses are the invasive procedure for cell harvesting, limited amounts of bone marrow, and reduced proliferation capacity with age [10]. Therefore, alternative sources containing cells with higher proliferative potency, capability of differentiation, and lower risk of viral contamination are being considered. Currently, other sources of MSCs can be readily isolated from many different tissues including adipose, cartilage, skin, muscle, and gestational tissues such as umbilical cord and placenta [11]. The human placenta is a very attractive source of MSCs for several advantages such as easy accessibility, noninvasive procedures, a high-yielding source of stem cells, and minimal ethical controversies $[12,13]$.

PL-hMSCs have been reported to have the characteristics matching human MSC defined in 2006 by Cell Committee of the International Society for Cellular Therapy (ISCT) [12]. In short, MSCs must adhere to plastic, express specific MSC cell surface markers, and have the potential of differentiating into chondrocytes, osteocytes, and adipocytes [14]. In addition, isolated PL-hMSCs represent a more homogeneous and primitive population that maintain MSC stemness compared to other tissues $[15,16]$. Several studies have indeed revealed that PL-hMSCs have more proliferative capacity, longer life span, and immunomodulatory potential compared to other sources $[17,18]$. Also, PL-hMSCs have a limited capacity to grow in cultures related to low telomerase activity, which is lost during proliferation, making them a safe product to be used in regenerative medicine [19]. Currently. PL-hMSCs have been studied in a variety of disorders such as neurological diseases, cancer, cardiac diseases as well as bone and cartilage diseases [20-24]. However, the increasing demand for PL-hMSCs for clinical trials makes high quality and large numbers of the cells mandatory. Therefore, it is necessary to explore safe and effective agents to improve the potential of PL-hMSCs for stem cell-based therapy in bone diseases.

Currently, several natural small compounds are being explored as new osteogenic inducers in stem cells. Andrographolide (AP), which is a diterpenoid lactone derived from Andrographis paniculata Nees, is one of the popular compounds that exerts several pharmacological activities including anti-inflammation, anti-oxidation, and immunomodulation [25-27]. It has been extensively used for treatments of inflammatory diseases such as fever, inflammation, diarrhea, and osteoarthritis [28, 29]. AP has been examined in various experimental studies on humans and animals indicating that it is safe and has less serious side effects $[25,30]$. Recently, we have reported the osteogenic effect of AP in mouse preosteoblast cell lines and the protective effect on bone loss in estrogen-deficient rats [31]. However, the effects of AP on PL-hMSCs are still unknown. Therefore, we aimed to investigate the potential role of AP in in vitro PL-hMSCs cell proliferation and in the ability to differentiate into osteoblasts. 


\section{Materials And Methods}

\section{Isolation and culture of mesenchymal stem cells derived from placenta}

Full-term normal human placentas were collected from pregnant women after normal deliveries at Thammasat Chalermprakiat Hospital. Written informed consents were obtained from the mothers. This study was approved by the Human Ethics Committee of Thammasat University No. 1 (Faculty of Medicine; No.071/2017), which was in accordance with the Declaration of Helsinki, the Belmont Report, and ICH-GCP. Placenta-derived cells were prepared as follows. The placental tissue was chopped into small pieces and incubated with $0.25 \%(\mathrm{w} / \mathrm{v})$ trypsin-EDTA (GIBCO ${ }^{\mathrm{Tm}}$, Invitrogen Corporation, USA) for 30 minutes at $37^{\circ} \mathrm{C}$. The chopped pieces were washed twice with PBS and cultured in DMEM $+10 \%(\mathrm{v} / \mathrm{v}) \mathrm{FBS}$ (GIBCO ${ }^{\text {TM }}$, Invitrogen Corporation, USA) in a $25 \mathrm{~cm}^{2}$ culture flask (Corning, USA). Cells were then cultured at $37^{\circ} \mathrm{C}$. To remove non-adherent cells, the media were changed every 3 days. The adherent cells were further cultured until colonies of fibroblast-like cells were obtained. For expansion, the cells were subcultured using $0.25 \%$ trypsin-EDTA. The morphology of PL-hMSCs was observed and photographed under an inverted microscope (Nikon Eclipse Ts2R, Japan). Culture cells were observed continuously to procure developing colonies of fibroblast-like cells.

\section{Immunophenotypical characterization of PL-hMSCs by flow cytometry}

The phenotype of PL-hMSCs was evaluated by flow cytometry (FACScalibur ${ }^{\text {TM }}$, Becton Dickinson, USA) and CellQuest ${ }^{\circledR}$ software (Becton Dickinson, USA). Native third to fifth passages of PL-hMSCs were trypsinized using $0.25 \%$ trypsin-EDTA and suspended in PBS. Cells were incubated with fluorochromelabeled mouse anti-human monoclonal antibodies: anti-CD45-FITC (Bio Legend, USA), anti-CD34-PE (Biolegend, USA), anti-CD90- PE (Bio Legend, USA), anti-CD73-PE (Bio Legend, USA), and anti-CD105-PE (BD Bioscience, USA) for 30 minutes at $4^{\circ} \mathrm{C}$ in the dark. After incubating with the antibodies, cell pellets were washed twice with PBS and fixed with $1 \%(\mathrm{w} / \mathrm{v})$ paraformaldehyde in PBS.

\section{Adipogenic and osteogenic differentiation ability of PL-hMSCs}

PL-hMSCs (3rd-6th passages) were used to evaluate their adipogenic and osteogenic differentiation potentials. Cells were cultured in 6-well plates with growth medium (10\% FBS+DMEM) at a density of $5 \times 10^{3}$ cells $/ \mathrm{cm}^{2}$. For adipogenic differentiation, after cells reached $70-80 \%$ confluence, the medium was replaced with adipogenic medium containing DMEM (high glucose) supplemented with 10\% FBS, $0.5 \mathrm{mM}$ isobutylmethylxanthine, $100 \mathrm{nM}$ dexamethasone, $1 \mu \mathrm{g} / \mathrm{ml}$ insulin solution and $100 \mu \mathrm{M}$ indomethacin (Sigma-Aldrich, USA). Adipogenic media were changed every 3 days and the generation of lipid droplets were revealed by Oil Red 0 staining (Sigma-Aldrich, USA) after treatment for 28 days. For osteogenic differentiation, after cells reached $\sim 90 \%$ confluence, the medium was changed to the osteogenic differentiation medium consisting of DMEM (low glucose) plus 10\% FBS, $100 \mathrm{nM}$ dexamethasone (Sigma-Aldrich, USA), $10 \mathrm{mM}$ ß-glycerophosphate (Sigma-Aldrich, USA), and $50 \mu \mathrm{g} / \mathrm{ml}$ ascorbic acid (Sigma-Aldrich, USA). Cells were cultured in the osteogenic differentiation medium for 21 days and the 
medium were changed every 3 days. Differentiated cells were analyzed by alizarin red staining and observed under an inverted microscope (Nikon Eclipse Ts2R, Japan).

\section{Cell viability and proliferation assays}

Cell viability was detected by the MTT method [32]. Briefly, PL-hMSCs were seeded at $1 \times 10^{3}$ cells/well in 96-well plates (Costa, Corning, USA) with growth medium. Twenty-four hours later, cells were treated with AP (Sigma-Aldrich, USA) dissolved in $0.05 \%$ methanol at the final concentrations of $0.1-50 \mu \mathrm{M}$ and incubated for $24-120$ hours. Cells in the same volume of untreated culture media containing $0.05 \%$ methanol were used as control. After incubating for the indicated times, cells were incubated with MTT $(0.5 \mathrm{mg} / \mathrm{ml})$ for 4 hours. The formazan precipitate was dissolved in $150 \mu \mathrm{L}$ DMSO, and the absorbance was detected at $570 \mathrm{~nm}$. The $\mathrm{IC}_{50}$ values were calculated according to the dose-dependent curves. All tests were repeated in at least three independent experiments. Cell viability (\%) was calculated against untreated control cells. Cell proliferation was measured using a bromodeoxyuridine (BrdU) cell proliferation assay kit (Sigma-Aldrich; Merck KGaA) according to the manufacturer's instruction. The measurements were performed in triplicates.

\section{ALP staining and enzyme activity assay}

PL-hMSCs were cultured in 6-well plates at a density of $5 \times 10^{3} / \mathrm{cm}^{2}$ in osteogenic condition for 14 days. For alkaline phosphatase (ALP) staining assay, the cultured cells were washed with PBS and fixed with $4 \%$ paraformaldehyde for 5 minutes at $4^{\circ} \mathrm{C}$. Then, 5 -bromo-4-chloro-3-indolylphosphate/nitro blue tetrazolium liquid substrate (BCIP/NBT; Sigma-Aldrich, USA) was added and incubated for 30 minutes at room temperature. The reactions were stopped by rinsing with deionized water and observed under a light microscope. (Nikon TS100, Japan). ALP activity assays were performed by using SensoLyte ${ }^{\circledR}$ pNPP Alkaline Phosphatase Assay Kit (Anaspec, Inc., USA). Briefly, the lysed cells were mixed with p-nitrophenyl phosphate (pNPP) substrate solution at room temperature for 30 minutes. After enzymatic reaction was stopped, absorbance values were measured at $405 \mathrm{~nm}$. ALP activity was calculated from a p-nitrophenol (pNP) standard curve and normalized with total protein concentration measured by using bicinchoninic acid (BCA) assay kit (Sigma-Aldrich, USA).

\section{Alizarin Red S staining}

To detect calcium deposition or mineralized matrix formation in osteoblasts, cells were washed with PBS then fixed with $4 \%$ paraformaldehyde. The fixed cells were stained with $2 \%$ Alizarin Red S for 20 minutes at room temperature, then washed twice with deionized water, and observed under a microscope.

\section{Luciferase reporter gene assay}

The effect of AP on Wnt/ $\beta$-catenin transcriptional activity was determined by luciferase reporter gene assay. HEK293T cells were seeded in 96 -well culture plates at a density of $2.5 \times 10^{3}$ cells/well and 
incubated for overnight. According to the instructions of the manufacturer, cells were then transiently transfected using Lipofectamine 2000 with TOPflash or FOPflash $(0.5 \mathrm{mg})$, Renilla luciferase reporter plasmid $(0.5 \mathrm{mg})$ and $\beta$-catenin-FLAG plasmid $(0.1 \mathrm{mg})$ for 24 hours. Cells were then treated with different concentrations of AP for 24 hours then cells were harvested with lysis buffer. The luciferase activities were measured with the dual-luciferase reporter assay system (Promega, Madison, WI, USA) using a luminometer (TECAN spark $10 \mathrm{M}$, TECAN, Mannedorf, Switzerland). The luciferase activity was normalized to Renilla luciferase activity as an internal control and expressed as the fold change compared with the cells transfected with the pcDNA3.1 empty vector.

\section{Total RNA isolation and quantitative PCR of genes}

Total RNA was isolated using Trizol reagent the instructions of the manufacturer (Trizol, Invitrogen). RNA was quantified by A260 and reverse transcription used $500 \mathrm{ng}$ of total RNA using an iScript select cDNA synthesis kit (Bio-Rad Laboratories Inc). Gene expressions were analyzed by quantitative RT-PCR using iTaq Universal SYBR Green Supermix (Bio-Rad Laboratories Inc) and performed in ABI step one plus and analysis software (Applied Biosystems, Foster City, CA, USA). Relative mRNA quantity was calculated by the comparative cycle threshold $(C T)$ method $(\triangle C T)$ using glyceraldehyde-3-phosphate dehydrogenase (GAPDH) as control. Sequences of primers for RT-PCR are shown in Table 1.

\section{Western blot analysis}

The expressions of active- $\beta$-catenin and $\beta$-catenin proteins were investigated by Western blot analysis. After seeding PL-hMSCs in 6-well plates and incubating with AP at the concentration 1, 2.5, 5 and $10 \mu \mathrm{M}$ for 24 hours, cells were harvested for protein assay. Briefly cells were lysed with RIPA lysis buffer with a protease and phosphatase inhibitor cocktail (Roche diagnostic $\mathrm{GmbH}$, Boehringer, Mannheim, Germany) and were incubated for 20 min on ice. Lysates were centrifuged to remove cell debris. Protein concentrations were determined using by bicinchoninic acid dye binding (BCA assay, Pierce, Rockford, IL). For western blot, each sample contained $20 \mu \mathrm{g}$ of protein. Lysates were diluted with $6 \mathrm{X}$ sample buffer, separated by $10 \%$ SDS-polyacrylamide gel electrophoresis, and transferred onto PVDF membranes. Membranes were blocked with $5 \%$ nonfat dried milk, and then incubated with primary antibodies overnight at $4^{\circ} \mathrm{C}$. Antibodies were used as following: anti-active- $\beta$-catenin (clone 8E7) (Millipore, Darmstadt, Germany), anti- $\beta$-catenin (Santa Cruz Biotechnology, Inc., Dallas, TX, USA), and anti- $\beta$-actin (Sigma-Aldrich, St. Louis, MO, USA). Membranes were then incubated with the horseradish peroxidaseconjugated secondary antibodies for 1 hour and visualized by enhanced chemiluminescence (Pierce ECL, Thermo- Fischer, Rockford, IL). The expression of $\beta$-actin was used as the control.

\section{Osteocalcin concentration determination}

PL-hMSCs were cultured and prepared for the ARS assay as described above. Cell supernatants were collected for the determinations. The levels of secreted osteocalcin were determined by an enzyme-linked immunosorbent assay in accordance with the manufacturer's recommended protocols (Elabscience 
Biotechnology Co., Wuhan, Hubei, China). Three duplicated wells were set for each group and the concentrations were calculated based on standard curve.

\section{Nanostring® nCounter assay}

Modulation of gene expression by AP on PL-hMSCs was determined by NanoString ${ }^{\circledR}$ nCounter Technology (NanoString Technologies, Seattle, WA, USA) using nCounter ${ }^{\circledR}$ PanCancer Panel. Multiplex gene expression analysis with 770 genes to assess proliferative and osteogenic genes of PL-hMSCs was performed. Hybridization of samples was performed, and the obtained products were run according to the manufacturer's instructions. Data were collected on the nCounter Sprint profiler and further evaluated by nSolver software, v4.0 analysis. Transcript copies were normalized using the geometric mean of 29 housekeeping genes for reference and normalization. Fifty threshold count value was the background thresholding parameter; the fold changes of gene expression were calculated comparing treated samples with untreated controls. Raw p-values from the differential expression analyses were used to assess gene expression data. All heat maps and data cluster sets were produced using the nCounter Analysis and Advanced Analysis packages in nSolver4.0 (NanoString Technologies, Seattle, WA, USA).

\section{Statistical analysis}

The data are presented as mean \pm standard error of the mean (SEM). Statistical comparisons were performed using the One-way ANOVA followed by a Newman-Keuls multiple comparison tests. P-value of less than 0.05 was considered to be statistically significant.

\section{Results}

\section{Characteristics of PL-hMSCs phenotypes}

PL-hMSCs were isolated and expanded in primary cultures and passaged for 3-5 times. We found that the cells exhibited typical fibroblastic-like morphology, which attached, spread, and displayed spindleshaped morphology on plastic surface of the tissue culture flasks (Fig. 1A). Further, the cells expressed typical surface markers according to the standard definition of MSCs including CD73, CD90 and CD105, but did not express hematopoietic markers including CD34 and CD45 (Fig. 1C). The results indicate that the cells used in this study are indeed PL-hMSCs.

Moreover, the differentiation potentials of PL-hMSCs were also examined. Under certain conditions, MSCs are characterized as multipotent cells which can differentiate into different cells. In our study, after PLhMSCs were cultured under adipogenic condition for 4 weeks, cells were changed from spindle shaped morphology to large round shaped cells showing the accumulation of lipid droplets in their cytoplasm (Fig. 1B). In contrast, lipid droplets were not found in the control cultured cells. Calcium deposits are an indication of successful in vitro bone formation and can be specifically visualized using alizarin red staining. In this study, the calcium depositions were detected in osteogenic treated cells after 3 weeks (Fig. 1B) but they were not found in control cells. These results show that PL-hMSCs had the potential to 
differentiate into adipocyte and osteoblast cells upon proper stimulations. Therefore, PL-hMSCs generated in our study met the MSCs criteria set by the International Society of Cellular Therapy and can be used for further investigations.

\section{Effect of AP on cell viability and proliferation}

Fig 2A. demonstrates cell viability of PL-hMSCs treated with AP in growth medium for 24-72 hours compared to control group. Interestingly, viability of the cells treated with 1-5 $\mu \mathrm{M}$ of AP were significantly increased compared to the control group $(P<0.05$ and $P<0.01)$ but were decreased at higher concentrations (10-50 $\mu \mathrm{M}$ AP) suggesting that AP exhibits cell toxicity at the concentration higher than 10 $\mu \mathrm{M}$. The half maximal inhibitory concentration ( $\mathrm{IC}_{50}$ values) of $\mathrm{AP}$ at 24,48 , and $72 \mathrm{~h}$ were $26.38 \pm 0.15$, $23.11 \pm 0.14$, and $19.23 \pm 0.26$, respectively. To avoid any cytotoxic effects, the maximum dose of AP used in further experiments was $10 \mu \mathrm{M}$. Of note, the enhancements of cell viability were associated with increases in cell proliferation as confirmed by BrdU assay (Fig2 B). We found that proliferations of PLhMSCs cultured in growth medium containing $1,2.5$ and $5 \mu \mathrm{M}$ of AP were significantly increased after treatment for $24,48,72,96$ and 120 hours compared to the control group $(P<0.05$ and $P<0.01)$. These results indicate that AP has a proliferative effect on PL-hMSCs. Moreover, we also examined the MSC characteristics of PL-hMSC at day 5 after treatment with $2.5 \mu \mathrm{M}$ of AP. Interestingly, the cells still showed MSC characteristics in both morphology and phenotypic surface markers (Fig. 2C and D). The results suggest that AP has the ability to increase in vitro MSCs expansion without alteration of the MSC stemness.

\section{AP increased the level and activity of $\beta$-catenin protein}

The levels of protein and luciferase activity of $\beta$-catenin were assessed to examine whether AP increased PL-hMSC proliferation via the Wnt/ $\beta$-catenin pathway. AP at 1 and $2.5 \mu \mathrm{M}$ significantly increased the levels of active $\beta$-catenin proteins/total $\beta$-catenin at 24 hours compared to the control (Fig. 3A). Of note, $\mathrm{AP}$ at 5 and $10 \mu \mathrm{M}$ seemed to increase the expression of active $\beta$-catenin proteins, the results were, however, not statistically significant. Moreover, $\beta$-catenin activity levels were augmented by AP (Fig. 3B). The direct target genes of Wnt/ $\beta$-catenin including c-myc, Axin-2, Cyclin D1 and Survivin were further examined. As shown in Fig. $3 \mathrm{C}, \mathrm{AP}$ at 2.5 and $5 \mu \mathrm{M}$ significantly enhanced the expressions of all these genes compared to the control whereas only Cyclin D1 was increased by a lower concentration $(1 \mu \mathrm{M})$. Based on these results, AP has proliferative effect on PL-hMSC, at least, via the Wnt/ $\beta$-catenin pathway.

\section{AP promoted osteogenic differentiation}

To examine if AP promotes osteoblastic differentiation of PL-hMSCs, its effect on the expression and activity of alkaline phosphatase (ALP), a major marker enzyme in the early and middle stage of osteoblastic differentiation, was determined. After treatment with AP at the concentrations of $1,2.5,5$ and $10 \mu \mathrm{M}$ for 14 days, the expressions of ALP were evidently elevated compared to control (Fig. 4A). To confirm the osteogenic effect of AP, ALP activity assay was further quantitatively determined at various 
stages of differentiation. As anticipated, AP at concentrations of 1, 2.5, 5 and $10 \mu \mathrm{M}$ showed increases in the expression and activity of ALP after treatment for 3, 7, 14, and 21 days. Consistent with the proliferative effect, $2.5 \mu \mathrm{M}$ AP appeared to be most effective by day 14, i.e., ALP activity was increased by $57.14 \pm 2.4 \%$, compared with the control (Fig 4B). In the late stages of osteoblast differentiation, the extracellular matrix was gradually mineralized due to calcium deposition or forming bone nodule. In Fig. 4C, AP at the concentrations of 1 to $10 \mu \mathrm{M}$ increased matrix mineralization of PL-hMSCs as evidenced by alizarin red staining. Moreover, bone formation was quantitatively determined by osteocalcin concentration assay. Of note, all doses of AP (1 to $10 \mu \mathrm{M})$ significantly increased osteocalcin concentration. Taken together, the results indicate that AP promotes both osteogenic differentiation and matrix mineralization of PL-hMSCs.

\section{Effects of AP on marker gene expressions of osteoblast differentiation and OPG/RANKL pathway}

On day 7 under the osteogenic condition, AP (1, 2.5 and $5 \mu \mathrm{M})$ caused a dose-dependent elevation of mRNA levels of RUNX2 and OSX, which are the major transcription factors required the early state for inducing osteogenesis in MSCs (Fig. 5A-B). The results suggests that AP affected an early phase of MSC differentiation into osteoblast lineage. In addition, the same dose range of AP increased the levels of the markers for middle phases of osteogenic differentiation, $A L P$ (Fig. 5C). Furthermore, the late-stage markers, Col1a1 and Osteocalcin, were significantly enhanced $(p<0.05)$ by days 14 and 21 , respectively (Fig. 5D-E). These results clearly indicate that AP was involved in all stages of osteogenic differentiation of PL-hMSCs.

OPG and RANKL proteins secreted from osteoblasts are important molecules that regulate the balance between bone formation and bone resorption, their mRNA expressions were further examined in osteoblasts derived from PL-hMSCs. As shown in Fig. 5F-G, AP at the concentrations of 1, 2.5 and $5 \mu \mathrm{M}$ significantly increased mRNA levels of $O P G$ compared to the control $(p<0.05)$ whereas the level of RANKL mRNA was suppressed by AP. The ratio of OPG/ RANKL mRNA expression, consequently, was significantly increased $(p<0.05)$. The results suggest that the OPG/RANKL signaling pathway is involved in AP-induced osteogenesis of PL-hMSCs.

\section{Effect of AP on changes of gene expression during osteogenic differentiation}

In order to get into detail of the pathways that AP enhanced PL-hMSC differentiation into osteoblasts, we performed an analysis of digital gene expression with 770 genes screening using NanoString nCounter. Hierarchical clustering revealed significant changes in mRNA of 37 genes in AP-treated group compared to those of the control group (Fig 6). These mRNA abundances were detected in ligands, receptors, or modulators of Wnt, TGF $\beta$, SMAD, and BMP. Moreover, a set of genes related to bone formation were also significantly upregulated such as COL1A1, COL1A2, COL5A1, COL5A2, FGF2, FGF7, IGF1R, and VEGFA etc. (Fig 6 and supplement data 1). These findings suggest that the mechanisms of action of AP on osteogenic differentiation of PL-hMSCs are involved with several pathways and molecules that are important for osteogenesis. 


\section{Discussion}

Previously, AP has been shown to have pro-osteogenic effects on bone marrow stem cells of mice and rats, whereas it prevented TNFa-induced suppression of osteoblast formation and mineralization [33]. Also, we recently reported that AP enhanced the osteogenic capacity of mouse pre-osteoblast cell lines [31]. However, the effect of AP on the proliferation and osteogenic differentiation of PL-hMSCs are still unknown. This study shows, for the first time, that AP promotes the proliferation and differentiation of $\mathrm{PL}$-hMSCs into bone cells via, at least, Wnt/ $\beta$-catenin, TGF $\beta / B M P / S M A D$, and FGF signaling pathways.

In recent years, human placental mesenchymal stem cells have become an attractive source of mesenchymal stem cells (MSCs) for tissue regeneration due to non-invasive procedures and less ethical criticisms [34]. In this study, the isolated PL-hMSCs met all the MSCs criteria set by the International Society of Cellular Therapy including adherence to plastic culture dishes, expression of a specific set of cell surface markers such as CD73, CD90 and CD105, but absence of hematopoietic markers such as CD34 and CD45. In addition, they have the ability to differentiate in vitro into adipocytes and osteoblasts (Fig.1) [14].

The key for using MSCs in therapeutic purposes is that they maintain the stemness of stem cells and can be expanded to meet the required amount of cells in laboratories. Although natural small molecules offer several compelling advantages, they might be unexpectedly cytotoxic to stem cells. Accordingly, a safe dose range was determined in this study. In the dose range of 1-10 $\mu \mathrm{M}, \mathrm{AP}$ exhibited no cytotoxicity and showed the proliferative effect on PL-hMSCs. The results are consistent with previous report the effective dose of on proliferation less than $10 \mu \mathrm{M}(4.46$ and $8.92 \mu \mathrm{M})$ increased rat BM-MSC proliferation [33]. Although AP promote PL-hMSCs proliferation, the specific MSC phenotype and surface protein markers were not affected suggesting that the stemness of the cells are maintained (Fig 2. C-D). Since Wnt signaling plays a critical role in adult proliferative and osteogenic differentiation of mesenchymal stem cells, we used Western blot and luciferase assay to determine the level and activity of $\beta$-catenin. As illustrated in Fig. 3 , AP significantly augmented both the level and activity of $\beta$-catenin indicating that $W n t / \beta$-catenin signaling plays a crucial role in this effect of AP. The results are consistent with our previous report in rat bone marrow stem cells [35]. Moreover, the mRNA expression levels of the direct target genes including $c-M y c$, Axin2, CyclinD1, and Survivin were also elevated by AP (Fig. 3) confirming that AP exerted its proliferative effect at least via Wnt/ $\beta$-catenin pathway.

The osteogenic differentiation of MSC is characterized by the expression of specific osteoblastic marker genes such as RUNX2, OSX, alkaline phosphatase (ALP), and type I collagen (Col1a1) followed by extracellular matrix synthesis and mineralization [36]. RUNX2, a master osteoblast transcription factor, is required to commit undifferentiated cells towards the osteoblast lineage and has a crucial role in regulating multiple genes involved in the osteogenesis [37]. In addition, osterix (OSX) is the second transcription factor required for osteoblast differentiation [38]. Thus, upregulations of both RUNX2 and OSX in this report suggest that AP induced changes of undifferentiated PL-hMSCs into the osteoblast lineage (Fig. 5). The results also corroborate the report that RUNX2 and OSX are downstream targets of 
Wnt/ $\beta$-catenin signaling to promotes mesenchymal stem cells differentiate into immature osteoblasts [37]. Further, our results revealed the elevation of mRNA expression levels of both col $1 \mathrm{a} 1$ and osteocalcin indicating that AP induced differentiation of the immature into mature osteoblasts. Also, AP promoted in vitro mineralization as indicated by alizarin red staining of mineralization nodules as well as the increase of osteocalcin production in PL-hMSCs (Fig. 4). Taken together, the increases in matrix mineralization and the bone specific genes and protein indicate the potential use of AP to promote PL-hMSC differentiation into mature osteoblasts and generate matrix mineralization.

The morphogenesis and remodeling of bone depend on the integrated activity of osteoblasts that form bone and osteoclasts that resorb bone [39]. OPG produced by osteoblasts has a crucial role in preventing excessive activation of osteoclasts by RANKL thereby maintaining bone homeostasis. Thus, the OPG/RANKL ratio may be used to indicate the potential of osteoblast in regulating bone remodeling process [40]. In our study, AP increased the OPG/RANKL ratio by increasing OPG expression level but decreasing RANKL expression suggesting that, in addition to promoting osteogenic differentiation, $\mathrm{AP}$ also enhanced the function of osteoblastic cells derived from PL-hMSCs.

Numerous signal transduction pathways and transcriptional factors, including the activation of Wnt/ $\beta$ catenin, TGF- $\beta / B M P$, and SMAD signaling, have been extensively reported to regulate osteoblastic MSC differentiation [41, 42]. To determine the molecular mechanisms for the action of AP on PL-hMSCs proliferation and differentiation, screening of genes involved in osteogenic differentiation were explored by a NanoString nCounter analysis. Results obtained from this data set revealed several importance pathways including Wnt, TGF $\beta$, BMP, and SMAD. Moreover, other genes related to these pathways such as FGF2, FGF7, IGF1, IFGBP3 and VEGFA were also upregulated by AP. The results are, therefore, consistent with the role of Wnt signaling in the induction of Runx2-dependent transcription of TGF $\beta 1$ receptors [43, 44]. The central role of the TGF $\beta / B M P$ axis in regulating mesenchymal stem cell differentiation into bone as well as extensive cross talk with other signaling pathways are well established $[42,45]$. Of these, the activity of several genes including Hedgehog, FGF2, FGF7 and IGF1 appeared to be increased in parallel with TGF $\beta / B M P$ during cell differentiation. FGF2 regulates the expression of PC1, the primary enzymatic generator of pyrophosphate in mineralizing cells, by direct regulation of Runx2 suggesting that TGF $\beta / B M P$ and FGF2 signaling cooperate to promote matrix mineralization later in differentiation [42]. Surprisingly, this analysis showed the upregulation of FGF7, which has recently been reported to promote new bone formation in rats [46] and facilitate osteogenic differentiation of embryonic stem cells through activation of ERK/Runx2 signaling [47]. Moreover, the elevations of SMAD2 and SMAD3 in our study are in line with the notion that SMAD2 and SMAD3 are the common mediators for TGF- $\beta$ signaling, which respond to TGF- $\beta$ receptors in the process of coupling bone formation and bone resorption to maintain normal bone homeostasis [45]. In addition to the genes involved in cell proliferation and differentiation, the genes related to bone formation such as COL1A1, COL1A2, COL5A1 and COL5A2 were enhanced by AP suggesting a strong potential of AP in promoting differentiation of PL-hMSCs to bone required for bone regeneration. However, it should be pointed out that our data from gene screening only give clue for the possible molecules and pathways by which AP promoted proliferation and differentiation of PLhMSCs. The detailed mechanisms require further investigations. 


\section{Conclusions}

This report is the first to demonstrate that AP at the concentration of less than $10 \mu \mathrm{M}$ promoted proliferation and osteogenic differentiation of PL-hMSCs via activation of, at least, Wnt/ $\beta$-catenin signaling pathway. The findings provide strong evidence that AP is a novel effective agent for expansion and induction of bone from PL-hMSCs for uses in stem cell-based therapy especially for bone regenerative medicine. Future studies are, however, required to investigate more specific mechanisms associated with the AP-mediated osteogenic differentiation of PL-hMSCs.

\section{Abbreviations}

AP: Andrographolide; ALP: Alkaline phosphatase: ARS: Alizarin Red S; BM-MSCs: Bone marrow-derived MSCs; BMP: Bone Morphogenetic Protein; FITC: Fluorescein isothiocyanate; MTT, 3-(4,5-dimethylthiazol2-yl)-2,5-diphenyl tetrazolium bromide; MSCs: Mesenchymal stem cells; OPG: Osteoprotegerin; PE: Phycoerythrin; PL-hMSCs: Human placenta-derived mesenchymal stem cells; RANKL: Receptor activator of nuclear factor kappa-B ligand; TGF- $\beta$ : Transforming growth factor-beta

\section{Declarations}

\section{Ethics approval and consent to participate}

This study was approved by the Human Ethics Committee of Thammasat University No. 1 (Faculty of Medicine; No.071/2017), which was in accordance with the declaration of Helsinki, the Belmont Report, and ICH-GCP.

\section{Consent for publication}

Not applicable.

\section{Availability of data and materials}

Data sharing not applicable to this article as no datasets were generated or analyzed during the current study.

\section{Competing interests}

The authors declare that there is no competing interests.

\section{Funding}

The authors gratefully acknowledge the financial support provided by Thammasat University Research Fund under the TU research Scholar (contract No. 2/7/2562), the Program Management Unit (Brain Power, Manpower), Office of National Higher Education Science Research and Innovation Policy Council, Thailand, and Center of Excellence in Stem Cell Research, Thammasat University. 


\section{Authors' contributions}

NP conducted the experiments. NB contributed to the study design, data analysis and drafting of the manuscript. KS conducted the experiments. PK, SK, and CT contributed to the data interpretation. DT contributed to study design, data acquisition, data analysis and interpretation, and manuscript writing. All authors read and approved the final manuscript. The authors declare that there is no conflict of interests in this work.

\section{Acknowledgements}

We thank Prof. Chumpol Pholpramool for critical reading, editing, and proofreading the manuscript.

\section{References}

1. Ager JW, Balooch G, Ritchie RO. Fracture, aging, and disease in bone. Journal of Materials Research. 2006;21(8):1878-92.

2. Boskey AL, Imbert L. Bone quality changes associated with aging and disease: a review. Ann N Y Acad Sci. 2017;1410(1):93-106.

3. Bianco P, Riminucci M, Gronthos S, Robey PG. Bone Marrow Stromal Stem Cells: Nature, Biology, and Potential Applications. STEM CELLS. 2001;19(3):180-92.

4. Infante A, Rodríguez $\mathrm{Cl}$. Osteogenesis and aging: lessons from mesenchymal stem cells. Stem Cell Res Ther. 2018;9(1):244.

5. Coipeau P, Rosset P, Langonné A, Gaillard J, Delorme B, Rico A, et al. Impaired differentiation potential of human trabecular bone mesenchymal stromal cells from elderly patients. Cytotherapy. 2009;11(5):584-94.

6. Nöth U, Osyczka AM, Tuli R, Hickok NJ, Danielson KG, Tuan RS. Multilineage mesenchymal differentiation potential of human trabecular bone-derived cells. Journal of Orthopaedic Research. 2002;20(5):1060-9.

7. Granero-Moltó F, Weis JA, Miga MI, Landis B, Myers TJ, O'Rear L, et al. Regenerative Effects of Transplanted Mesenchymal Stem Cells in Fracture Healing. STEM CELLS. 2009;27(8):1887-98.

8. Chanda D, Kumar S, Ponnazhagan S. Therapeutic potential of adult bone marrow-derived mesenchymal stem cells in diseases of the skeleton. J Cell Biochem. 2010;111(2):249-57.

9. Stenderup K, Justesen J, Clausen C, Kassem M. Aging is associated with decreased maximal life span and accelerated senescence of bone marrow stromal cells. Bone. 2003;33(6):919-26.

10. Boskey AL, Imbert L. Bone quality changes associated with aging and disease: a review. Ann N Y Acad Sci. 2017;1410(1):93-106.

11. Montesinos JJ, Flores-Figueroa E, Castillo-Medina S, Flores-Guzmán P, Hernández-Estévez E, FajardoOrduña G, et al. Human mesenchymal stromal cells from adult and neonatal sources: comparative 
analysis of their morphology, immunophenotype, differentiation patterns and neural protein expression. Cytotherapy. 2009;11(2):163-76.

12. Caruso M, Evangelista M, Parolini O. Human term placental cells: phenotype, properties and new avenues in regenerative medicine. Int J Mol Cell Med. 2012;1(2):64-74.

13. Yen BL, Huang H-I, Chien C-C, Jui H-Y, Ko B-S, Yao M, et al. Isolation of Multipotent Cells from Human Term Placenta. STEM CELLS. 2005;23(1):3-9.

14. Dominici M LBK, Mueller I, Slaper-Cortenbach I, Marini F, Krause D, Deans R, Keating A, Prockop Dj, Horwitz E. Minimal criteria for defining multipotent mesenchymal stromal cells. Cytotherapy. 2006;8(4):315-7.

15. In 't Anker PS, Scherjon SA, Kleijburg-van der Keur C, de Groot-Swings GM, Claas FH, Fibbe WE, et al. Isolation of mesenchymal stem cells of fetal or maternal origin from human placenta. Stem Cells. 2004;22(7):1338-45.

16. Hass R, Kasper C, Böhm S, Jacobs R. Different populations and sources of human mesenchymal stem cells (MSC): A comparison of adult and neonatal tissue-derived MSC. Cell Communication and Signaling. 2011;9(1):12.

17. Zhu Y, Yang Y, Zhang Y, Hao G, Liu T, Wang L, et al. Placental mesenchymal stem cells of fetal and maternal origins demonstrate different therapeutic potentials. Stem Cell Res Ther. 2014;5(2):48.

18. Huang Q, Yang Y, Luo C, Wen Y, Liu R, Li S, et al. An efficient protocol to generate placental chorionic plate-derived mesenchymal stem cells with superior proliferative and immunomodulatory properties. Stem Cell Res Ther. 2019;10(1):301.

19. Macias MI, Grande J, Moreno A, Domínguez I, Bornstein R, Flores Al. Isolation and characterization of true mesenchymal stem cells derived from human term decidua capable of multilineage differentiation into all 3 embryonic layers. American Journal of Obstetrics \& Gynecology. 2010;203(5):495.e9-.e23.

20. Zhao $P$, Ise $H$, Hongo $M$, Ota $M$, Konishi I, Nikaido T. Human amniotic mesenchymal cells have some characteristics of cardiomyocytes. Transplantation. 2005;79(5):528-35.

21. Portmann-Lanz CB, Schoeberlein A, Portmann R, Mohr S, Rollini P, Sager R, et al. Turning placenta into brain: placental mesenchymal stem cells differentiate into neurons and oligodendrocytes. American journal of obstetrics and gynecology. 2010;202(3):294.e1-e11.

22. Shafiee A, Fisk NM, Hutmacher DW, Khosrotehrani K, Patel J. Fetal endothelial and mesenchymal progenitors from the human term placenta: potency and clinical potential. Stem cells translational medicine. 2015;4(5):419-23.

23. Kusuma GD, Menicanin D, Gronthos S, Manuelpillai U, Abumaree MH, Pertile MD, et al. Ectopic Bone Formation by Mesenchymal Stem Cells Derived from Human Term Placenta and the Decidua. PLoS One. 2015;10(10):e0141246.

24. Nogami M, Tsuno H, Koike C, Okabe M, Yoshida T, Seki S, et al. Isolation and characterization of human amniotic mesenchymal stem cells and their chondrogenic differentiation. Transplantation. 2012;93(12):1221-8. 
25. Jayakumar T, Hsieh C-Y, Lee J-J, Sheu J-R. Experimental and Clinical Pharmacology of Andrographis paniculata and Its Major Bioactive Phytoconstituent Andrographolide. Evidence-based Complementary and Alternative Medicine : eCAM. 2013;2013:846740.

26. Li Y, He S, Tang J, Ding N, Chu X, Cheng L, et al. Andrographolide Inhibits Inflammatory Cytokines Secretion in LPS-Stimulated RAW264.7 Cells through Suppression of NF-KB/MAPK Signaling Pathway. Evidence-based Complementary and Alternative Medicine : eCAM. 2017;2017:8248142.

27. Abu-Ghefreh $\mathrm{AaA}$, Canatan $\mathrm{H}$, Ezeamuzie $\mathrm{Cl}$. In vitro and in vivo anti-inflammatory effects of andrographolide. International Immunopharmacology. 2009;9(3):313-8.

28. Islam MT. Andrographolide, a New Hope in the Prevention and Treatment of Metabolic Syndrome. Frontiers in pharmacology. 2017;8:571.

29. Zhang L, Bao M, Liu B, Zhao H, Zhang Y, Ji X, et al. Effect of Andrographolide and Its Analogs on Bacterial Infection: A Review. Pharmacology. 2020;105(3-4):123-34.

30. Bothiraja C, Pawar AP, Shende VS, Joshi PP. Acute and subacute toxicity study of andrographolide bioactive in rodents: Evidence for the medicinal use as an alternative medicine. Comparative Clinical Pathology. 2013;22(6):1123-8.

31. Tantikanlayaporn D, Wichit P, Suksen K, Suksamrarn A, Piyachaturawat P. Andrographolide modulates OPG/RANKL axis to promote osteoblastic differentiation in MC3T3-E1 cells and protects bone loss during estrogen deficiency in rats. Biomedicine \& Pharmacotherapy. 2020;131:110763.

32. Tantikanlayaporn D, Robinson LJ, Suksamrarn A, Piyachaturawat P, Blair HC. A diarylheptanoid phytoestrogen from Curcuma comosa, 1,7-diphenyl-4,6-heptadien-3-ol, accelerates human osteoblast proliferation and differentiation. Phytomedicine : international journal of phytotherapy and phytopharmacology. 2013;20(8-9):676-82.

33. Jiang $T$, Zhou B, Huang L, Wu H, Huang J, Liang T, et al. Andrographolide Exerts Pro-Osteogenic Effect by Activation of Wnt/ $\beta$-Catenin Signaling Pathway in Vitro. Cellular physiology and biochemistry : international journal of experimental cellular physiology, biochemistry, and pharmacology. 2015;36(6):2327-39.

34. Arthur A, Zannettino A, Gronthos S. The therapeutic applications of multipotential mesenchymal/stromal stem cells in skeletal tissue repair. Journal of cellular physiology. 2009;218(2):237-45.

35. Jiang T, Zhou B, Huang L, Wu H, Huang J, Liang T, et al. Andrographolide Exerts Pro-Osteogenic Effect by Activation of Wnt/ $\beta$-Catenin Signaling Pathway $\langle b><i>i n$ Vitro $</ i></ b>$. Cellular Physiology and Biochemistry. 2015;36(6):2327-39.

36. Rutkovskiy A, Stensløkken K-O, Vaage IJ. Osteoblast Differentiation at a Glance. Med Sci Monit Basic Res. 2016;22:95-106.

37. Komori T. Regulation of osteoblast differentiation by transcription factors. J Cell Biochem. 2006;99(5):1233-9.

38. Nakashima K, Zhou X, Kunkel G, Zhang Z, Deng JM, Behringer RR, et al. The novel zinc fingercontaining transcription factor osterix is required for osteoblast differentiation and bone formation. 
Cell. 2002;108(1):17-29.

39. Kong YY, Penninger JM. Molecular control of bone remodeling and osteoporosis. Experimental Gerontology. 2000;35(8):947-56.

40. Boyce B, Xing L. Biology of RANK, RANKL, and osteoprotegerin. Arthritis Res Ther. 2007;9(Suppl $1: S 1)$.

41. Hojo H, Ohba S, Chung U-i. Signaling pathways regulating the specification and differentiation of the osteoblast lineage. Regenerative Therapy. 2015;1:57-62.

42. Wu M, Chen G, Li Y-P. TGF- $\beta$ and BMP signaling in osteoblast, skeletal development, and bone formation, homeostasis and disease. Bone Research. 2016;4(1):16009.

43. van den Bosch $M H$, Blom $A B$, van Lent $P L$, van Beuningen $H M$, Blaney Davidson EN, van der Kraan $\mathrm{PM}$, et al. Canonical Wnt signaling skews TGF- $\beta$ signaling in chondrocytes towards signaling via ALK1 and Smad 1/5/8. Cellular Signalling. 2014;26(5):951-8.

44. Long F, Chung U-i, Ohba S, McMahon J, Kronenberg HM, McMahon AP. Ihh signaling is directly required for the osteoblast lineage in the endochondral skeleton. Development. 2004;131(6):1309.

45. Guo X, Wang X-F. Signaling cross-talk between TGF- $\beta$ /BMP and other pathways. Cell Research. 2009;19(1):71-88.

46. Poudel SB, Bhattarai G, Kim J-H, Kook S-H, Seo Y-K, Jeon Y-M, et al. Local delivery of recombinant human FGF7 enhances bone formation in rat mandible defects. Journal of Bone and Mineral Metabolism. 2017;35(5):485-96.

47. Jeon Y-M, Kook S-H, Rho S-J, Lim S-S, Choi K-C, Kim H-S, et al. Fibroblast growth factor-7 facilitates osteogenic differentiation of embryonic stem cells through the activation of ERK/Runx2 signaling. Molecular and Cellular Biochemistry. 2013;382(1):37-45.

\section{Tables}

Table 1. Sequences of primers for quantitative RT-PCR analyses 


\begin{tabular}{|c|c|c|}
\hline Gene & Sequence $\left(5^{\prime}\right.$ to $\left.3^{\prime}\right)$ & Length of product (bp) \\
\hline \multirow[t]{2}{*}{ Runx2 } & F- 5'-CCTCGGAGAGGTACCAGATG-3' & 247 \\
\hline & R- 5'-TTCCCGAGGTCCATCTACTG-3' & \\
\hline \multirow[t]{2}{*}{ osx } & F- 5'-GCCAGAAGCTGTGAAACCTC-3' & 161 \\
\hline & R- 5'- GCTGCAAGCTCTCCATAACC-3' & \\
\hline \multirow[t]{2}{*}{$A L P$} & F- 5'- ССTTGCTCACTСАСТСАСТСC-3' & 182 \\
\hline & R- 5'- TTTTTTTTGCCGTTCCAAAC-3' & \\
\hline \multirow[t]{2}{*}{ Osteocalcin } & F-5'-GTGCAGAGTCCAGCAAAGGT-3' & 152 \\
\hline & R- 5'-TCAGCCAACTCGTCACAGTC-3' & \\
\hline \multirow[t]{2}{*}{ Col1a1 } & F-5'-AGGGCCAAGACGAAGACATCCC-3' & 108 \\
\hline & R-5'-TGTCGCAGACGCAGATCCG-3' & \\
\hline \multirow[t]{2}{*}{$O P G$} & F- 5'-AACGCCAACACAGCTCACAAGAAC-3' & 160 \\
\hline & R- 5'-TGCTCGAAGGTGAGGTTAGCATGT-3' & \\
\hline \multirow[t]{2}{*}{ RANKL } & F- 5'- ATCGTTGGATCACAGCACATC-3' & 152 \\
\hline & R- 5'-AGACTCACTTTATGGGAACCAGA-3' & \\
\hline \multirow[t]{2}{*}{$C-m y c$} & F- 5'-ATGGCCCATTACAAAGCCG-3' & 175 \\
\hline & R- 5'-TTTCTGGAGTAGCAGCTCCTAA-3' & \\
\hline \multirow[t]{2}{*}{ AXIN2 } & F- 5'-CCTGGCTCCAGAAGATCACA-3' & 120 \\
\hline & R- 5'-AGCATCCTCCGGTATGGAAT-3' & \\
\hline \multirow[t]{2}{*}{ Survivin } & F- 5'-TGAGAACGAGCCAGACTTG-3' & 87 \\
\hline & R- 5'-TGTTCCTCTATGGGGTCGTCA-3' & \\
\hline \multirow[t]{2}{*}{ Cyclin D1 } & F- 5'-GATCAAGTGTGACCCGGACTG-3' & 101 \\
\hline & R- 5'-CCTTGGGGTCCATGTTCTGC-3' & \\
\hline \multirow[t]{2}{*}{ GAPDH } & F- 5'-GAGTCAACGGATTTGGTCGT-3' & 238 \\
\hline & R- 5'-TTGATTTTGGAGGGATCTCG-3' & \\
\hline
\end{tabular}

\section{Figures}


A

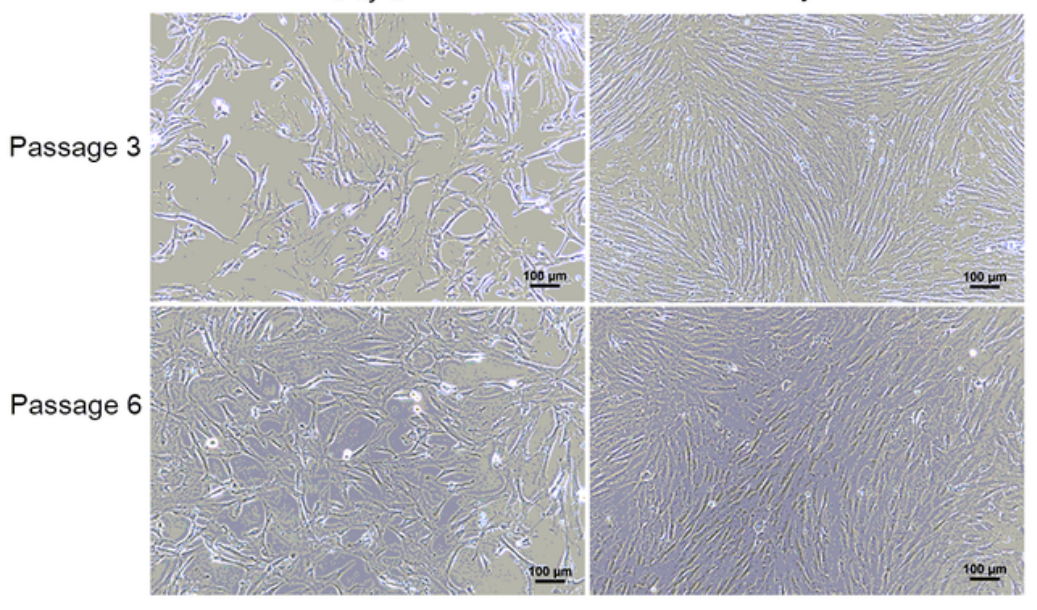

B

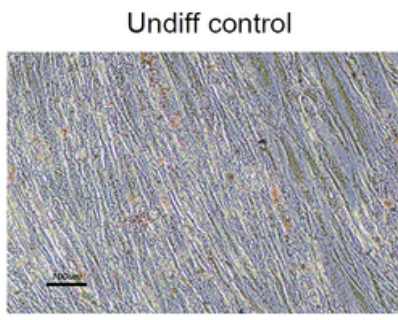

Undiff control

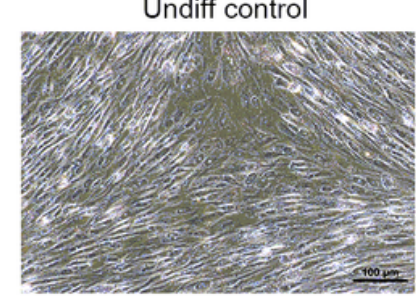

Adipogenic differentiation

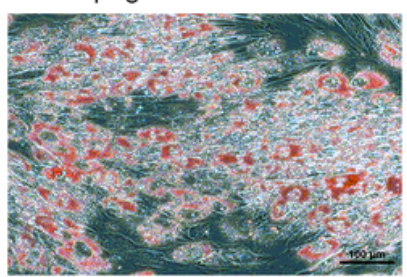

C
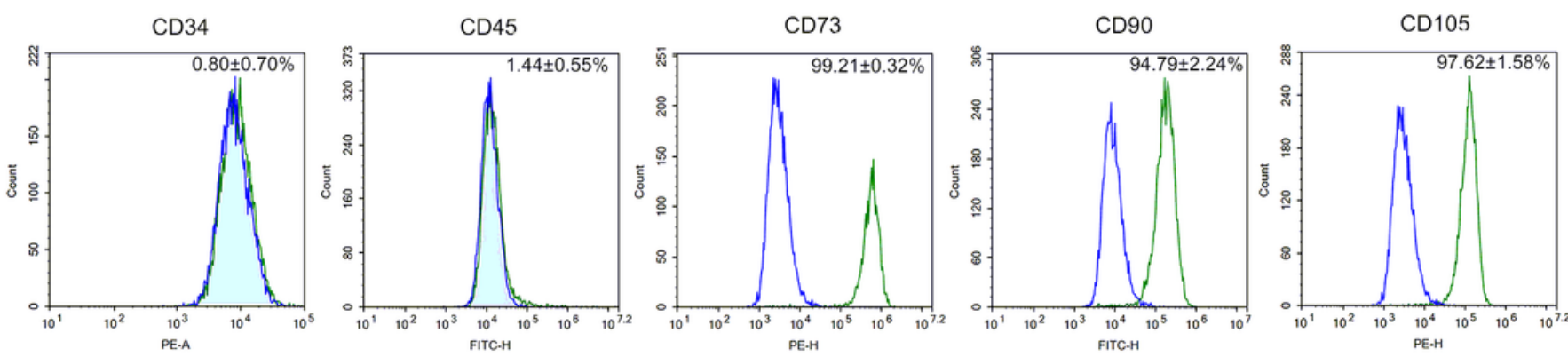

\section{Figure 1}

Identification of human placenta-derived mesenchymal stem cells (PL-hMSCs). A: Appearance and growth of PL-hMSCs at 3rd and 6th passages on day 2 and 5, respectively. B: Differentiation potentials of PL-hMSCs; representative images of alizarin red staining cultured in osteogenic induction medium after 21 days compared to control condition (left) and oil red 0 staining cultured in adipogenic induction medium after 28 days compared to control medium (right); scale bar, $100 \mu \mathrm{m}$. C: The expressions of typical cell surface markers of MSC in PL-hMSCs. Detection of typical cell surface markers of MSC in PLhMSCs (green) and in isotype controls (blue) by flow cytometry. PL-hMSCs expressed CD73, CD90, and CD105 but not CD34 and CD45. 
A

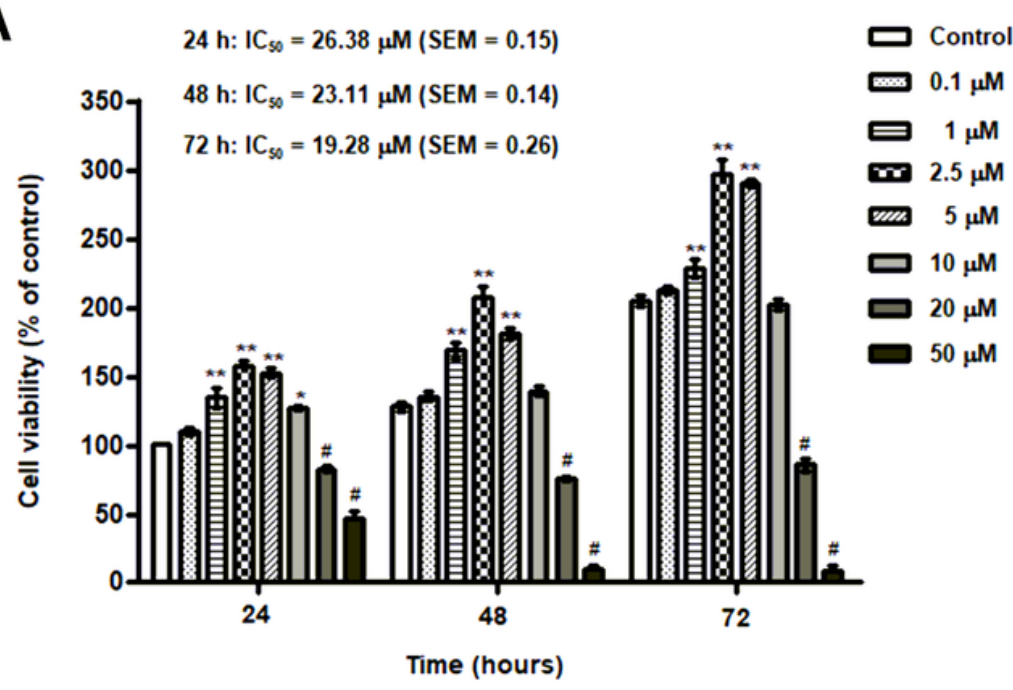

C

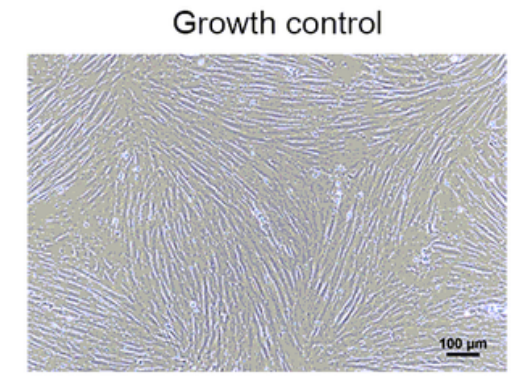

B

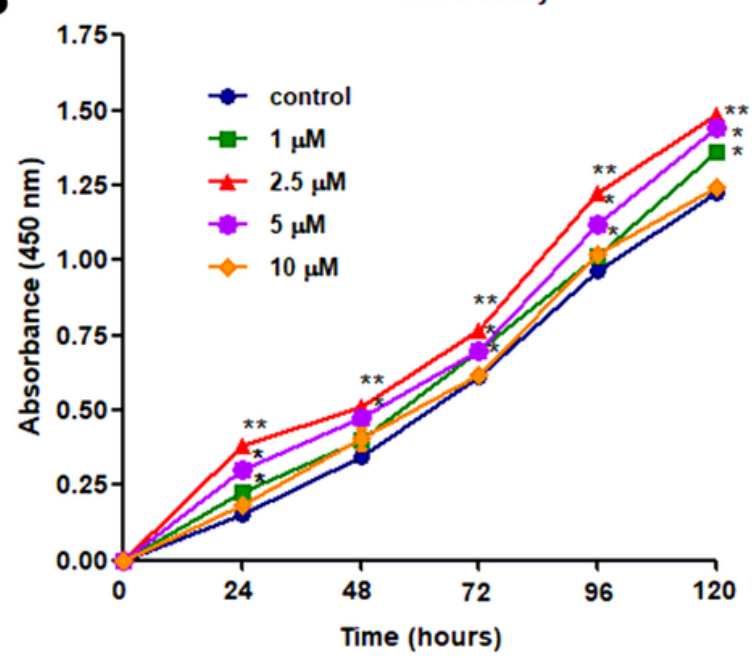

D

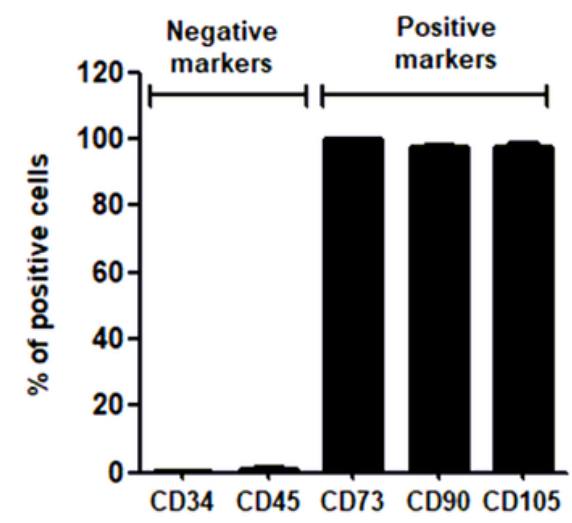

Figure 2

Effect of AP on cell viability and proliferation of PL-hMSCs. A: Cell viability of PL-hMSCs in growth medium with various concentrations of $\mathrm{AP}(0.1-50 \mu \mathrm{M})$ at 24,48 and 72 hours. B: Cell proliferation of PLhMSC in growth medium with various concentrations of $\operatorname{AP}(1,2.5,5,10 \mu \mathrm{M})$ at 24, 48, 72, 96 and 120 hours. Data are presented as the means of independent experiments $(n=4) .{ }^{*}<0.05,{ }^{\star * \star} P<0.01$, and $\star \star \star P<0.001$ significant increases compared to the control group at the same time point, $\# p<0.05$, significant decreases compared to the control group at the same time point. C Cell morphology of PLhMSCs after treatment with $2.5 \mu \mathrm{M}$ AP for 5 days. D The \% of cell surface markers expressions in PLhMSCs after treatment with $2.5 \mu \mathrm{M}$ AP for 5 days performed by flow cytometry (positive for CD73, CD 90 and CD105; negative for CD34 and CD45). Data are expressed as mean $\pm S E M ; n=3$. 
A

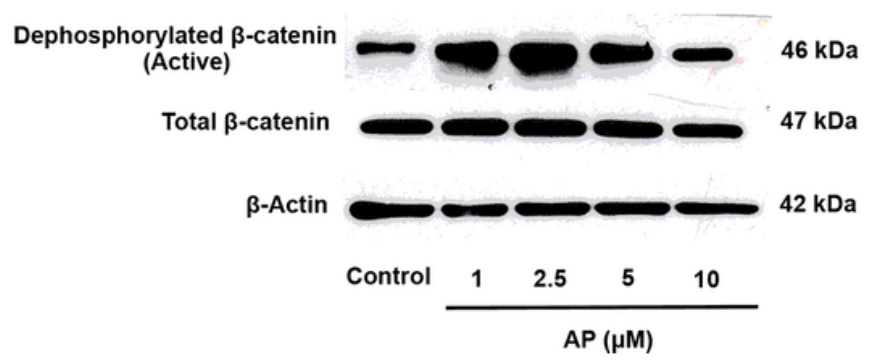

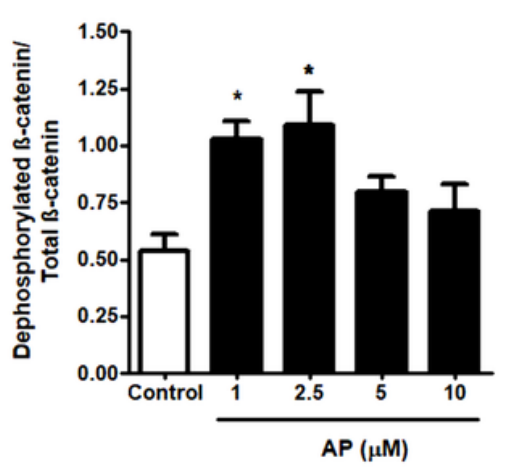

B

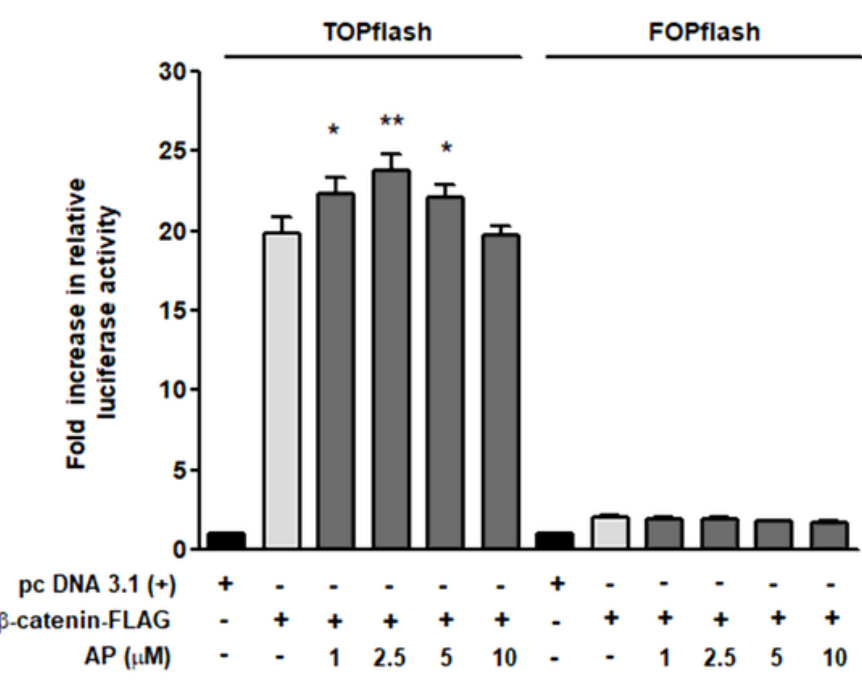

C

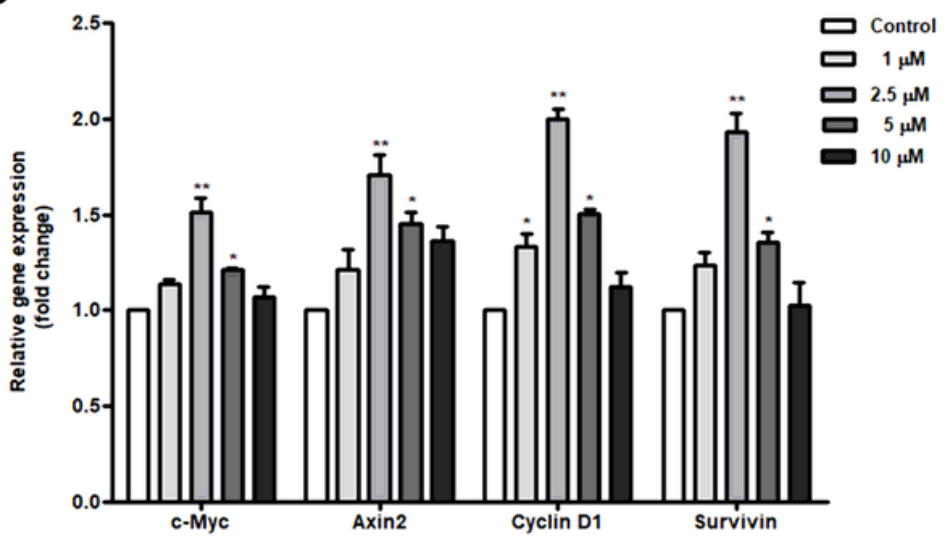

Figure 3

Effect of AP on Wnt/ $\beta$-catenin during proliferation of PL-hMSCs. A: Western blot assay showing the expressions of dephosphorylated $\beta$-catenin (active), total $\beta$-catenin and $\beta$-actin after treatment with AP for 24 hours (left panel) and the band intensity of dephosphorylated $\beta$-catenin (active)/total $\beta$-catenin ratio (normalized with $\beta$-actin; right panel). B: Luciferase activity assay of $\beta$-catenin after treatment with AP for 24 hours. The results are expressed as relative luciferase units compared with the cell transfected with $\beta$ catenin-FLAG vector with vehicle control. The relative firefly luciferase activity units (RLUs) were then measured and normalized with Renilla luciferase activity. Data are expressed as fold changes compared with pcDNA3.1-transfected cells. C: The mRNA expressions of the direct target genes of $\mathrm{Wnt} / \beta$-catenin including c-Myc, Axin2, Cyclin D1 and Survivin. Each value is the mean $\pm \mathrm{SEM} ;(\mathrm{n}=3) .{ }^{\star} \mathrm{p}<0.05,{ }^{\star \star} \mathrm{p}<0.01$, compared to the control group. 
A

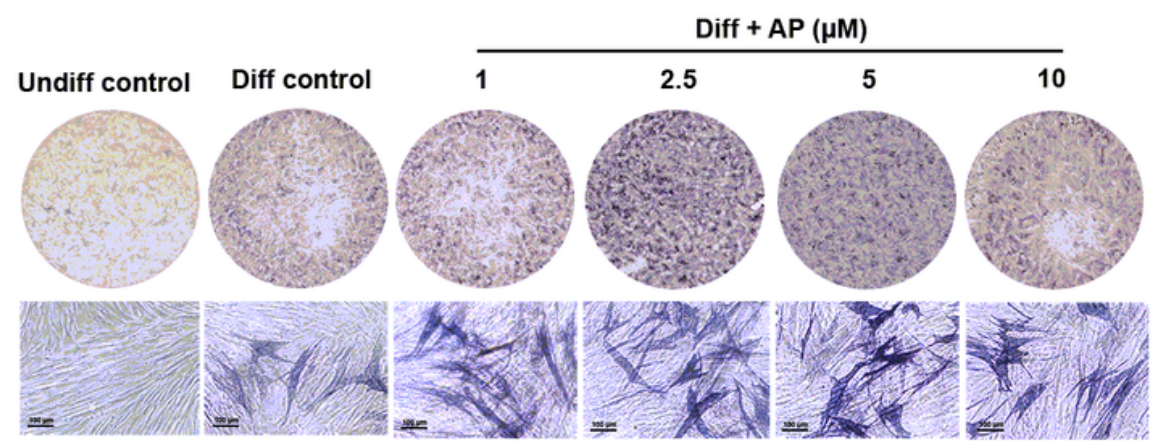

Diff + AP $(\mu M)$
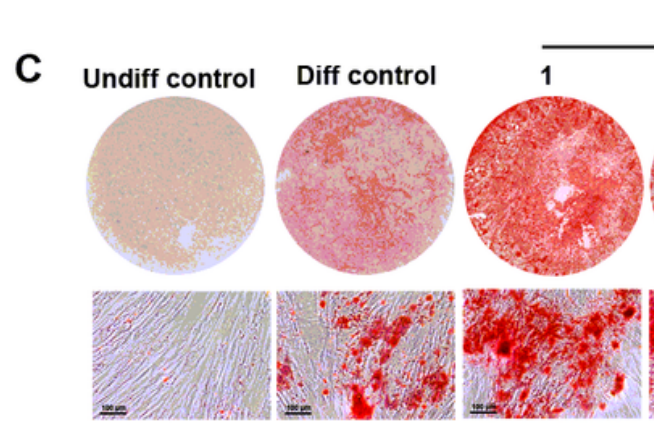

B

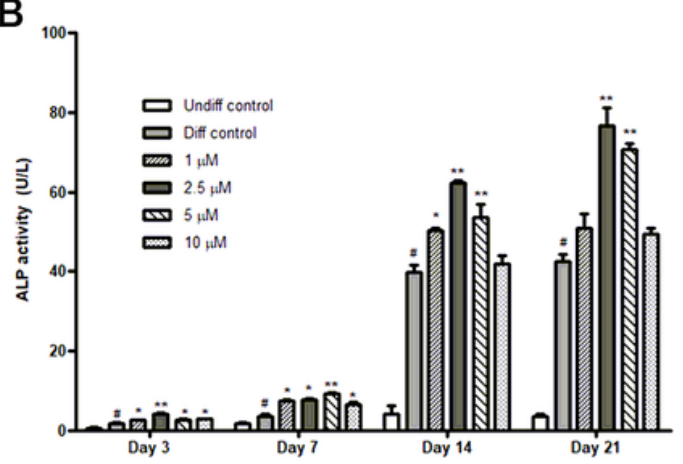

D

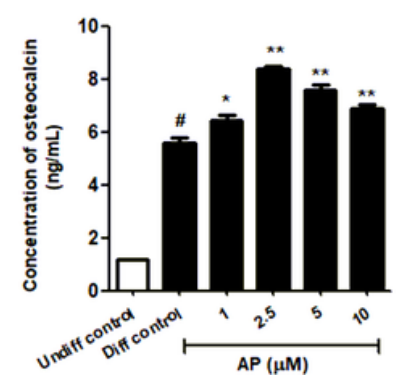

Figure 4

Effect of AP on osteogenesis of PL-hMSCs. A: Alkaline phosphatase (ALP) expression in PL-hMSCs after culture in osteo-inductive conditions with or without AP (1-10 $\mu \mathrm{M})$ for 14 days. B: Quantitative intracellular ALP activity in PL-hMSCs after culture in osteo-inductive conditions with or without AP (1-10 $\mu \mathrm{M})$ for 3-21days. C: Matrix mineralization visualized by alizarin red staining after culture in osteoinductive conditions with or without AP (1-10 $\mu \mathrm{M})$ for 21 days. D: Osteocalcin concentration in PL-hMSCs after culture in osteo-inductive conditions with or without AP (1-10 $\mu \mathrm{M})$ for 21 days. Each value shown in $B$ and $D$ represents the mean \pm SEM $(n=3)$. \#p $<0.05$, the differentiation control group compared to the undifferentiation control group, ${ }^{\star} p<0.05 * * p<0.01$, the AP treated group compared to the differentiation control group. 

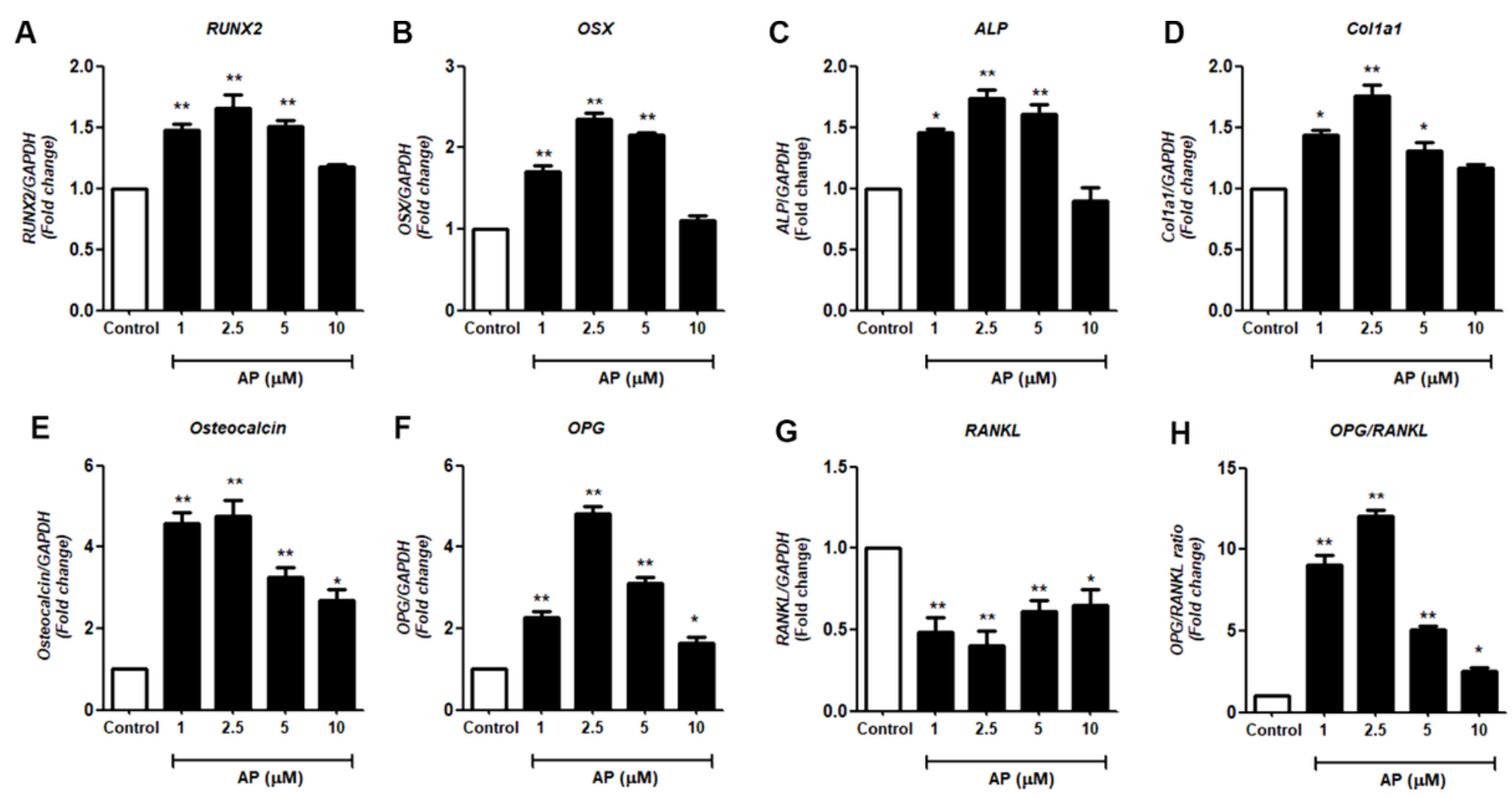

Figure 5

Effect of AP on osteoblast-marker gene expressions during osteoblast differentiation. The mRNA expressions of osteoblast marker genes in PL-hMSC derived osteoblastic cells after culture in osteogenic media with or without AP at the indicated concentrations and times: Expressions of mRNA were determined relative to GAPDH by quantitative RT-PCR. A. RUNX2 (day 7); B. OSX (day 7); C. ALP (day 14); D. Col1a1 (day14); E. Osteocalcin (day 21); F. OPG (day 21); G. RANKL (day 21); and H. the ratio of RANKL/OPG (day 21). Each value is the mean \pm SEM; $(n=3)$. ${ }^{*} p<0.05,{ }^{* *} p<0.01$, compared to the control group. 


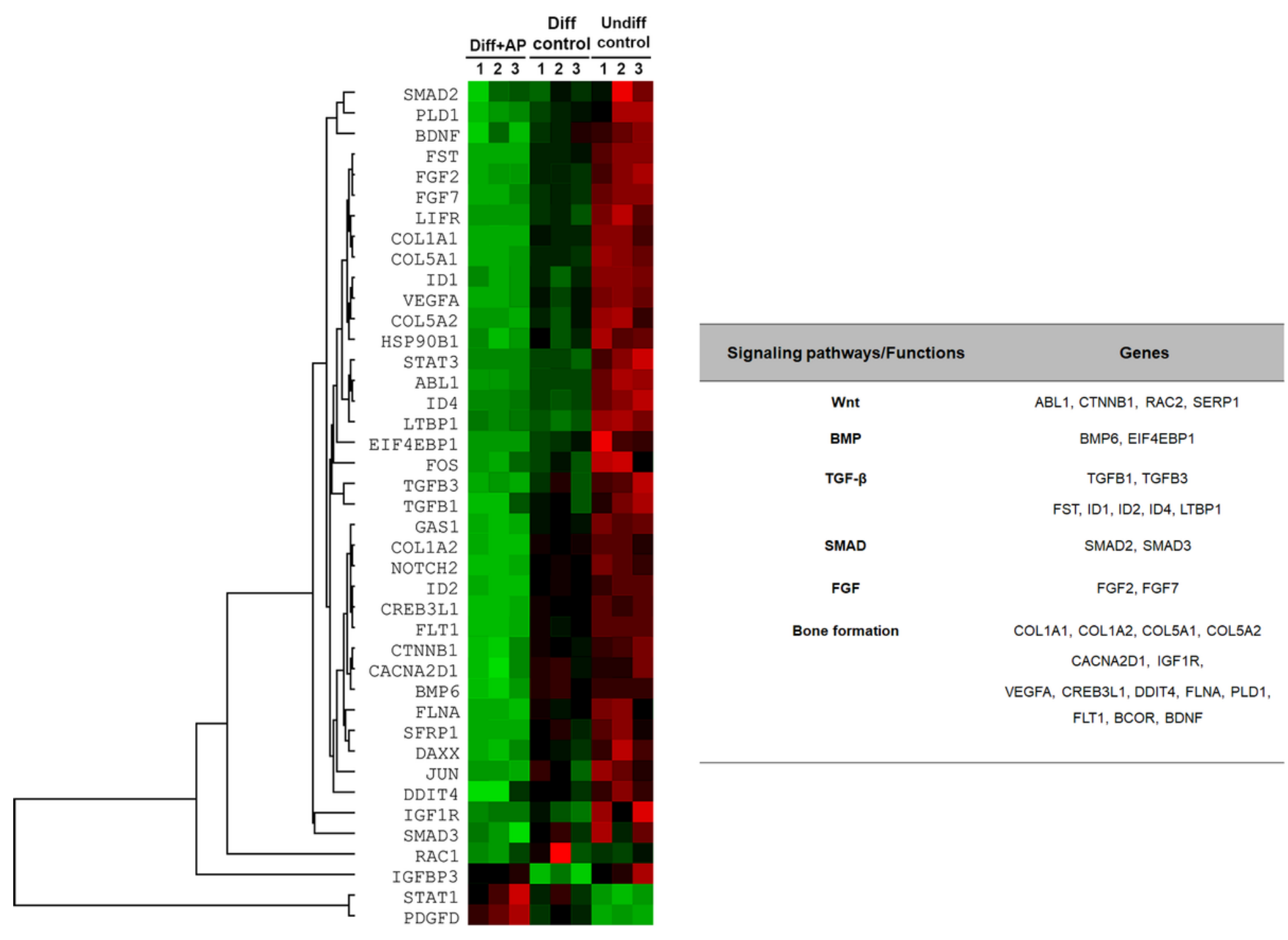

Figure 6

NanoString analysis of gene-related mRNAs during AP-enhanced osteogenic differentiation of PL-hMSCs. Triplicate samples of total mRNA isolated from PL-hMSCs at day 14 were analyzed using a NanoString Code Set. Left panel shows a heatmap of the 37 candidate genes differentially expressed between growth medium or undifferentiation control (Undiff control), osteo-inductive medium or differentiation control (Diff control), and osteo-inductive medium treated with $2.5 \mu \mathrm{M}$ AP (Diff+AP). Right panel shows the summary of gene enrichment analysis of the upregulated genes by AP treatment that show statistical significance $(P<0.05)$ compared to differentiation control.

\section{Supplementary Files}

This is a list of supplementary files associated with this preprint. Click to download.

- Supplementdata1.xlsx 